\title{
Perusing The Headwaters Of Diversity Among University Presidents
}

Dawn Wallace, Southeastern Louisiana University, USA

Michael C. Budden, Southeastern Louisiana University, USA

Connie B. Budden, Southeastern Louisiana University, USA

Josie Walker, Southeastern Louisiana University, USA

\begin{abstract}
Females and minorities are gaining clout in higher education as the numbers of graduates in each of these groups indicate. Diversity among university presidents is a reality. Indications are that the number of women receiving advanced degrees will continue to grow for some time. Low estimates of graduation rates among women and minorities from years ago do not hold. The impacts of this reality in higher education will continue to be felt for some time.
\end{abstract}

\section{INTRODUCTION}

$\mathrm{n}$ the years since Congress passed Title IX of the Higher Education Amendments Act in 1972, statistics indicate that women and minorities have made strides in educational participation and persistence. For example, although males received a greater number of degrees at all levels from 1869-1986, females have consistently achieved more degrees since 1986 (see Figure 1). Table 1 indicates that just 4 years after Title IX legislation was enacted, white students received $81 \%$ of doctoral degrees. However, minority students have attained a greater proportion of doctoral degrees over the past 30 years.

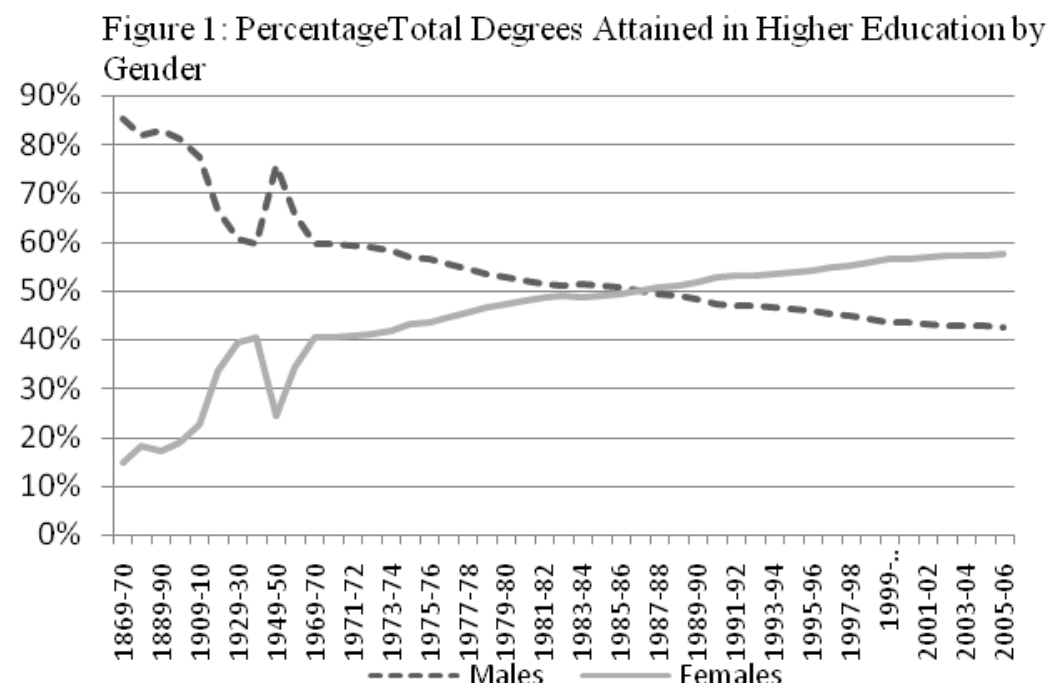

Source: NCES, 2007

The proportion of doctorates awarded to women in the United States was 15.1 percent in 1920, but declined to 13.0 percent in 1940 , the year that marked the $103^{\text {rd }}$ year of women's participation in higher education (see Figure 2). In 1999, the Chronicle of Higher Education estimated that women's doctoral attainment would not exceed 41 percent in the next decade. However, between the years 2000-2006, the percentage of women participating in 
higher education increased from $45-49$ percent. It is estimated that women will surpass men soon in doctoral degree attainment and will represent 60 percent of all degree recipients (NCES, 2007).

Figure 2: PercentageTotal Doctoral Degrees Attained in Higher Education by Gender

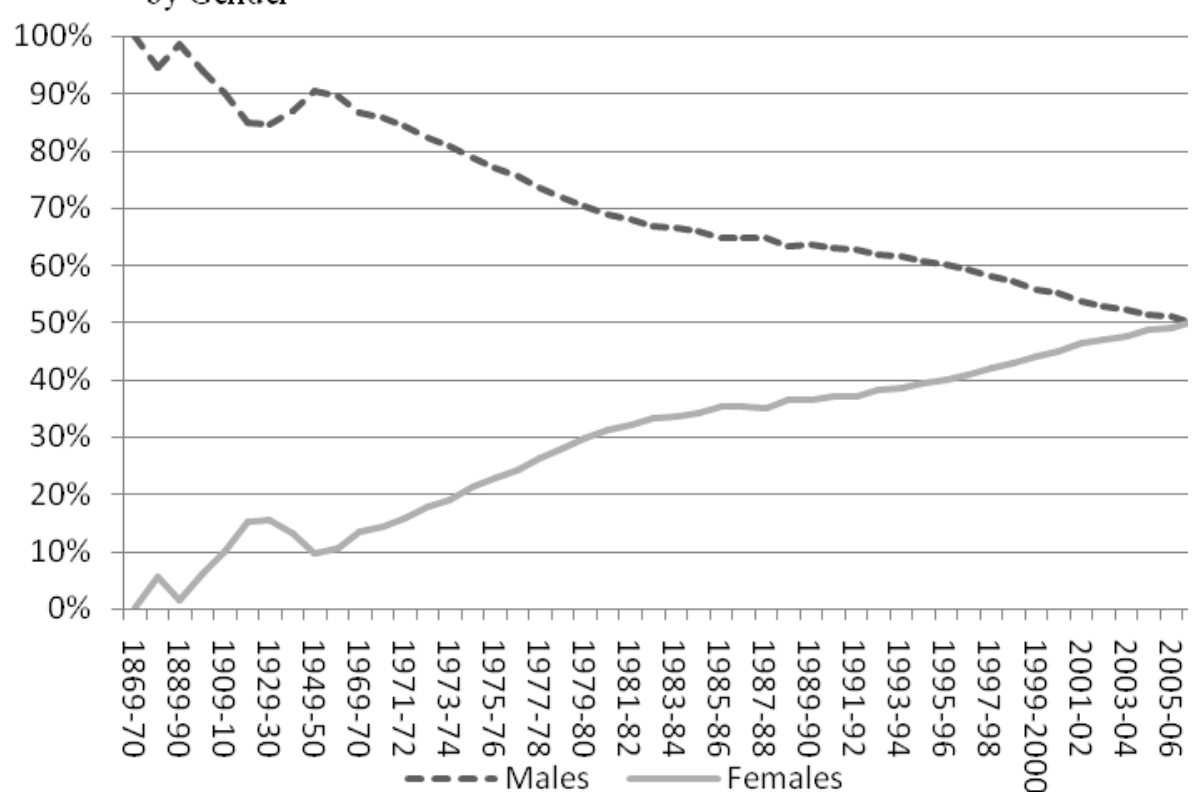

Source: NCES, 2007

\begin{tabular}{|c|c|c|c|c|c|c|}
\hline \multicolumn{7}{|c|}{ of student: Selected years, 1976-77 through 2005-06 } \\
\hline & \multicolumn{6}{|c|}{ Percentage distribution of degrees conferred } \\
\hline & White & Black & Hispanic & $\begin{array}{c}\text { Asian/ Pacific } \\
\text { Islander }\end{array}$ & $\begin{array}{c}\text { American } \\
\text { Indian/ Alaska } \\
\text { Native }\end{array}$ & $\begin{array}{c}\text { Non- resident } \\
\text { alien }\end{array}$ \\
\hline 1976-77 & 81.1 & 3.8 & 1.6 & 2.0 & 0.3 & 11.3 \\
\hline $1980-81$ & 78.9 & 3.9 & 1.4 & 2.7 & 0.4 & 12.8 \\
\hline 1989-90 & 68.3 & 3.0 & 2.0 & 3.2 & 0.3 & 23.2 \\
\hline 1990-91 & 65.8 & 3.2 & 1.9 & 3.8 & 0.3 & 25.0 \\
\hline $1991-92$ & 64.5 & 3.0 & 2.0 & 3.9 & 0.3 & 26.2 \\
\hline $1992-93$ & 63.6 & 3.2 & 2.0 & 3.7 & 0.3 & 27.2 \\
\hline 1993-94 & 63.0 & 3.2 & 2.1 & 4.7 & 0.3 & 26.7 \\
\hline $1994-95$ & 62.7 & 3.8 & 2.2 & 6.1 & 0.3 & 25.0 \\
\hline $1995-96$ & 62.2 & 3.7 & 2.2 & 5.9 & 0.4 & 25.6 \\
\hline 1996-97 & 62.3 & 4.1 & 2.4 & 5.8 & 0.4 & 25.0 \\
\hline 1997-98 & 62.6 & 4.5 & 2.8 & 5.1 & 0.4 & 24.6 \\
\hline 1998-99 & 63.2 & 4.8 & 3.0 & 5.2 & 0.4 & 23.4 \\
\hline 1999-2000 & 62.1 & 5.0 & 2.9 & 5.4 & 0.4 & 24.2 \\
\hline $2000-01$ & 61.1 & 4.9 & 3.4 & 5.8 & 0.4 & 24.4 \\
\hline 2001-02 & 60.9 & 5.4 & 3.2 & 5.3 & 0.4 & 24.7 \\
\hline $2002-03$ & 60.2 & 5.5 & 3.4 & 5.3 & 0.4 & 25.3 \\
\hline 2003-04 & 58.3 & 6.0 & 3.4 & 5.4 & 0.4 & 26.4 \\
\hline $2004-05$ & 57.5 & 5.8 & 3.5 & 5.5 & 0.5 & 27.3 \\
\hline $2005-06$ & 56.4 & 5.6 & 3.4 & 5.8 & 0.4 & 28.5 \\
\hline
\end{tabular}

Source: NCES, 2007 
Given demonstrated achievement as students in higher education, many researchers have argued that women and minorities are still too underrepresented in higher education work environments (Glazor-Raymo, 1999; Sandler, 1993). Banks (1995) states, "In terms of advanced training, degrees held, number of years in the profession, and total numbers in the pool from which administrators are drawn, there is no justification for the small numbers of women and minority educational leaders." However, Banks's research was conducted almost 13 years ago, a timeframe during which much has happened.

This paper explores women and minority participation in higher education leadership positions. Specifically, this research targets university presidents, the gatekeepers of academia. The purpose of this research is three-fold; to determine representation of women and minorities among university presidents; to explore the educational background women and minority presidents possess compared to their white male counterparts; and to learn if women and minorities reach their positions of university president at the same rates as white males.

\section{METHODOLOGY}

This research project was conducted in Fall 2007 and Spring 2008. The majority of information obtained was gathered from the World Wide Web. Many university presidents have resumes and other professional and personal information posted on their university or system websites. In addition to searching online, emails asking for information unobtainable through the web were sent to several presidents.

Overall, data was collected on 676 individuals serving as president of four-year colleges and universities in the United States. However, due to missing data, the objectives of this study were explored using data from 614 individuals. The data collected included university name, president name, gender, race, terminal degree and year earned, years from terminal degree to presidency, other degrees and professional training, and other administrative positions held.

\section{RESULTS}

Objective 1: Determine demographic representation among presidents of higher education institution. The participants included 571 males (84\%) and 97 females (16\%). The males consisted of 444 White, 52 African American, 8 Hispanic, 3 Native American, and 10 from other nationalities. The females consisted of 79 White, 13 African American, 4 Hispanic, and 1 from an unknown nationality. Table 2 provides the total representation by race and gender.

\begin{tabular}{|l|c|c|c|c|c|c|}
\hline \multicolumn{9}{|c|}{ Table 2: Study Representation by Race and Gender } \\
\hline \multicolumn{2}{|c|}{ Race } & \multicolumn{2}{c|}{ Male } & \multicolumn{2}{c|}{ Females } & \multicolumn{2}{c|}{ Total } \\
\hline & Number & $\mathbf{\%}$ & Number & \% & Number & \% \\
\hline White & 444 & 72 & 79 & 13 & 523 & 85 \\
\hline African American & 52 & 8 & 13 & 2 & 65 & 10 \\
\hline Hispanic & 8 & 1 & 4 & 1 & 12 & 2 \\
\hline Native American & 3 & $<1$ & 0 & 0 & 3 & $<1$ \\
\hline Other/Unknown & 10 & 2 & 1 & 1 & $<1$ & $<3$ \\
\hline
\end{tabular}

Objective 2: Degrees Earned and Universities Represented. The second objective of the study was to determine the types of degrees that women and minorities earned compared to their male counterparts, as well as the universities where most of the study participants received their terminal degrees. Table 3 displays the type of degrees earned by race and gender.

Investigating the highest degree earned by the presidents, it is apparent that Ph.D. holders account for the largest number (435) of degrees. Individuals with law degrees (52) and doctoral degrees ( Ed.D.; 41) garnered second and third place respectively among the university presidents. It is of note that 41 presidents had only a Master's degree or less. 


\begin{tabular}{|c|c|c|c|c|c|c|c|c|c|c|c|}
\hline & able 3: & Type & Degre & Earne & by $\mathbf{R a}$ & 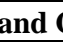 & nder & & & & \\
\hline & \multirow[b]{2}{*}{ Total } & \multicolumn{2}{|c|}{ White } & \multicolumn{2}{|c|}{$\begin{array}{c}\text { African } \\
\text { American }\end{array}$} & \multicolumn{2}{|c|}{ Hispanic } & \multicolumn{2}{|c|}{$\begin{array}{c}\text { Asian/ } \\
\text { Pacific } \\
\text { Islander }\end{array}$} & \multicolumn{2}{|c|}{ Other } \\
\hline & & $\mathbf{M}$ & $\mathbf{F}$ & $\mathbf{M}$ & $\mathbf{F}$ & $\mathbf{M}$ & $\mathbf{F}$ & $\mathbf{M}$ & $\mathbf{F}$ & $\mathbf{M}$ & $\mathbf{F}$ \\
\hline Ph.D. & 435 & 307 & 56 & 38 & 11 & 8 & 3 & 1 & & 10 & 1 \\
\hline $\mathrm{JD} / \mathrm{LL}$ & 52 & 39 & 10 & & 3 & & & & & & \\
\hline Ed.D. & 41 & 25 & 8 & 5 & & & 1 & 1 & & & 1 \\
\hline D. Min./Theology & 19 & 18 & & 1 & & & & & & & \\
\hline MD/Other Medical & 11 & 8 & 1 & 2 & & & & & & & \\
\hline Other Doctorate Degree & 5 & 3 & & 2 & & & & & & & \\
\hline M.Ed. & 3 & 3 & & & & & & & & & \\
\hline MA & 11 & 11 & & & & & & & & & \\
\hline MBA & 15 & 13 & 1 & 1 & & & & & & & \\
\hline Other Master's Degree & 15 & 11 & 2 & & 1 & & & 1 & & & \\
\hline No Master's or Doctorate & 7 & 6 & 1 & & & & & & & & \\
\hline
\end{tabular}

Table 4 indicates the top 10 universities where study participants received their highest degrees. The top 5 schools producing women and minority university presidents were, Harvard University, University of Wisconsin, Columbia University, Indiana State University and Michigan State University. Michigan State University was the only one among the top women and minority producing schools which did not attain top ten status among all presidential producers.

Table 4: Terminal Degree University, All Participants

\begin{tabular}{|c|c|c|c|c|c|c|c|c|c|c|}
\hline \multirow[b]{2}{*}{ Terminal University } & \multicolumn{4}{|c|}{ FM } & \multicolumn{5}{|c|}{$\mathbf{M}$} & \multirow[b]{2}{*}{ Total } \\
\hline & $\mathbf{A A}$ & Hisp & Other & White & $\mathbf{A A}$ & Hisp & Native & Other & White & \\
\hline Harvard & 1 & & & 1 & 3 & & & 1 & 18 & 24 \\
\hline University of Wisconsin & 1 & & & 2 & 1 & & & & 12 & 16 \\
\hline Yale & & & & 1 & 2 & & & & 13 & 16 \\
\hline University of Illinois & & & & 1 & 2 & & & & 12 & 15 \\
\hline Ohio State University & 2 & & & & 1 & & & & 8 & 11 \\
\hline Florida State University & & & & 1 & 2 & & & & 7 & 10 \\
\hline Indiana State University & & & & 2 & 2 & & & & 6 & 10 \\
\hline Stanford University & & & & 2 & & & & & 8 & 10 \\
\hline Columbia University & 1 & 1 & & 1 & 2 & & & & 5 & 10 \\
\hline University of Chicago & & & & 2 & 1 & & & & 7 & 10 \\
\hline TOTAL & 5 & 1 & 0 & 13 & 16 & 0 & 0 & 1 & 96 & 132 \\
\hline$\%$ of own race population & $38 \%$ & $25 \%$ & $0 \%$ & $16 \%$ & $31 \%$ & $0 \%$ & $0 \%$ & $10 \%$ & $22 \%$ & $20 \%$ \\
\hline
\end{tabular}

Objective 3: Years to Presidency. The third objective of this study was to determine if women and minorities achieved their presidency in the same average number of years as white males. For the 408 participants in the study where this data was available, the total average years from terminal degree to presidency was 21.98 . In looking at males and females, the average number of years to obtain presidency were 21.86 and 22.61 , respectively. Similarly, when comparing the mean time to presidency by white and minority presidents, the difference in time is less than one year. With both women and minorities now obtaining presidencies in similar time frames (less than one year's difference), there appears to be no indication of a problem. However, these numbers may be skewed by the low number of minorities in the pool. Finally, the statistics indicate the number of years that it takes to achieve presidency from the terminal degree has increased. Participants who have served the longest terms had the shortest times to presidency. This could be explained by the fact that the number of doctoral degrees attained increases each year, making the pool of candidates for presidencies more competitive. 


\section{LIMITATIONS}

The university presidents represented in this study could be described as a convenience sampling of presidents in U.S. institutions; albeit, a rather large convenience sample. The presidents included do not include presidents of all institutions of higher education, but rather a large cross-section of institutions. Every state in the U.S. had institutions included in this study. Since it is not a random sample, generalization to all institutions of higher education is discounted.

\section{DISCUSSION}

The results of this research yielded interesting and useful findings. First, the statistics indicate women are underrepresented in higher education presidency positions. When taking into consideration the average time from terminal degree to presidency, women are not receiving presidential appointments at the same rate as degree attainment. Specifically, 22 years ago, which is the average time from terminal degree to presidency; women received $35 \%$ of doctoral degrees. However, they only represent $16 \%$ of the population of presidents in this study. It should be noted that some professional fields are experiencing a drop out of women, as women leave career tracks in lieu of more family time, flexible time or less pressures.

Indeed, Himmelsbach (2008) laments the significant drain of female IT professionals. Himmelsbach references Harvard's report, The Athena Factor which examines the female exodus among science, engineering and technology fields. Luna and Medina (2006) reference a study that found that a rebalancing of personal and professional lives was common among women returning to faculty status after administration. Such personal reprioritizing by women may play a major role in the apparent shortfall of women presidents. Then too, some of the shortfall may be due to risk aversion behaviors of women, to perceptions of hostile work environments, to an unwillingness of females to mentor other women, to discriminatory practices and for other reasons.

For minority groups, the percent of degree attainment and presidential attainment presents a different picture. For instance, 22 years ago African Americans represented only 3.7\% of doctoral degree holders. In the present study, they accounted for $10 \%$ of presidents. Hispanics represented doctoral attainment at $2.2 \%$ of the higher education community. Today, they represent $2.0 \%$ of presidents. Native Americans, with only 0.04 doctorates 22 years ago, can count themselves among $1 \%$ of presidents today. So among minority populations, one could argue that minority presidents are proportionately represented.

For type of degree attained, the Ph.D. is overwhelmingly the most popular degree for all race and gender groups. However, it should be noted while there are more male presidents in fields generally underrepresented by women, such as law, medical, and theological fields, men also outnumber women in representing presidential positions attained with an Ed.D., a degree in a field with predominately female representation. Also, the presidents who achieved their positions without a doctoral degree were predominately male.

Knowledge of the universities where presidents received their terminal degrees provides a very useful look at which institutions of higher education are responsible for producing presidents. Those entering graduate schools that have a desire to pursue administrative tracks in higher education will find this information of interest.

One assertion in arguments about inequality is that women and minorities have to "work harder" to achieve the same results as their male counterparts. However, in this study, the statistics indicate that women and minorities achieve presidential status within one year of white male counterparts. Indeed, if one were to exclude those who have served as president for longer than 10 years, the small gap among white males, females and minorities is further reduced. Further research may be able to reveal if women and minorities had to spend more time in administration, publish more, attain additional educational achievements, or achieve other accomplishments in order to attain their current positions. 


\section{CONCLUSION}

Overall, this study provides a look at where women and minorities stand in the higher education presidency arena. More pointedly, this research begs the question, "Where are the women?" The results of the study should serve as a challenge to fill the void. Future research could shed more light on the situation by providing an analysis of salary comparisons, looking at rankings of universities, and also exploring additional professional information about university presidents. This, and further research, can paint a picture of what it takes for women and minorities to achieve these top positions in higher education.

\section{REFERENCES}

1. Banks, C. (1995). Gender and Race as Factors in Educational Leadership and Administration. (ERIC Document Reproduction Service No. ED 382 699)

2. Glazer-Raymo, J. (1999). Shattering the myths: Women in academe. Baltimore, MD: John Hopkins University Press.

3. Himmelsbach, V. (2008, August). Why women are leaving IT. ITWorld Canada. Can be found at www.ITWorldCanada.com.

4. Luna, G. and Medina, L. (2006, Summer). Coming full circle: Mid Career Women Leaving Administration and Returning to Faculty. Advancing Women Leadership Online Journal, Vol. 21.

5. National Center for Education Statistics (NCES, 2007). Digest of Education Statistics. Retrieved from http://nces.ed.gov/programs/digest/2007menu tables.asp.

6. Sandler, B. (1993; orig. 1986). The campus climate revisited: Chilly for women faculty, administrators, and graduate students. In J. Glazer, E. Bensimon, \& B. Townsend (Eds.), Women in higher education: A feminist perspective (pp. 175-203). Needham Heights, MA: Ginn. 